\title{
Risk and social vulnerability: how engineering can engage more effectively with climate change
}

\author{
Abbas H. El-Zein * \\ Geoenvironmental Engineering, School of Civil Engineering, University of Sydney, NSW, Australia
}

\section{Edited by:}

Rob Swart, Alterra, Netherlands

\section{Reviewed by:}

Busineni Devasena, Sri

Venkateswara Veterinary University, India

Sarah Bell, University College

London, UK

*Correspondence:

Abbas H. El-Zein, Geoenvironmental

Engineering, School of Civil

Engineering, University of Sydney,

Building J05, Sydney, NSW 2006,

Australia

e-mail: abbas.elzein@sydney.edu.au
Engineering practice, education and research are bound to be important elements in society's response to climate change. While a number of other disciplines such as economics, agriculture, urban planning and geoscience, are critical to the development of mitigation policies, the designs and processes engineers create in the transport, mining, energy, building and waste management sectors will be key in determining atmospheric concentrations of greenhouse gasses over the coming decades. Similarly, the way landscapes, buildings, neighborhoods and cities are built or rebuilt, will undoubtedly be a major part of adaptation to higher temperatures, rising sea levels and more extreme weather events. The paper discusses some of the barriers that prevent engineering education and practice from fully and productively engaging with the challenges raised by climate change. The paper recommends an expansion of the solution set to which engineering students and graduates are exposed, a better understanding by engineering students of the politics of technology and possible biases of engineers, and more engagement on the part of engineers with the social and ecological embeddedness of technology.

Keywords: vulnerability, engineering education, adaptation to climate change, mitigation to climate change, technology

\section{INTRODUCTION}

One of the remarkable aspects of the proposed actions for the mitigation of, and adaptation to, anthropogenic climate change is the extent to which they draw on knowledge across a large number of conventional academic disciplines, professional practices and social groups. For example, adapting to higher average temperatures and longer spells of more intense heat waves draws out a range of responses, some of which are shown in Table 1. Even a cursory examination of the kind of expertise required to assess, compare and choose from the solution set listed in Table 1, yields a list that includes urban planners, economists, social scientists, epidemiologist, climatologists, mechanical engineers, civil engineers, medical and public health professionals, architects, politicians, social workers, municipal officers, legal experts and so on. Clearly, who is likely to be involved in a particular action will depend on the specific context, including scope and time horizon of the intervention as well as its institutional and geographical scales. No single profession or discipline can be expected to carry alone the skills, know-how and thought processes required to tackle climate-related challenges. While the obvious approach to such multi-disciplinary problems is to engage multi-disciplinary teams in tackling them, two questions nevertheless arise. First, are the modes of thinking, professional training, biases and self-interests of any particular discipline conducive or not to such multi-disciplinary engagement? Second, do the practitioners of a given profession possess the attributes and skills required to navigate this complex solution set and help make comparisons and choices between them? In this paper, I discuss these questions in relation to engineering and suggest ways in which engineers can better engage with the multiple dimensions of climate change. The strong technological dimension of most actions on climate change makes these questions especially pertinent to engineers.

\section{ENGINEERING RESEARCH ON CLIMATE CHANGE}

Research on climate change by engineering scholars and institutions has grown significantly over the last three decades, both in absolute values of number of research publications, and as a proportion of all engineering research output (see Figure 1). Engineers are already making major contributions to the development of responses to climate change and a number of engineering organizations and firms have incorporated climate change problems in their strategic planning (e.g., Royal Academy of Engineering, 2011; Dalton et al., 2012). However, there has been little debate as to whether engineering institutions and curricula are well placed to tackle this challenge as fully and productively as needed.

\section{RISK vs. VULNERABILITY}

Risk assessment and risk management are intrinsic parts of engineering practice. Starting from an understanding of the technologies underpinning the production and distribution of basic services (e.g., housing, communications, transport, supply of energy, water, and food), engineers are usually well versed in methodologies assessing the likelihood of a breakdown of technology, in simple or complex systems, and implementing 
Table 1 | Examples of actions available to planners and policy-makers for tackling higher average temperatures and more frequent and/or more intense heat waves.

\begin{tabular}{ll}
\hline Action (list is indicative, not exhaustive) & $\begin{array}{l}\text { Professionals likely } \\
\text { to be Involved (list } \\
\text { is indicative, not } \\
\text { exhaustive) }\end{array}$
\end{tabular}

Medical interventions to deal with

Medical and health

physiological heat stress in emergency rooms

professionals;

epidemiologists

Public health programs to inform and advise on action during high-temperature spells

Medical and health professionals; epidemiologists

Heat-warning systems based on synoptic weather categories associated with high

Climate and weather mortality and morbidity

scientists; public health professionals; epidemiologists

City-wide, targeted emergency programs to be activated prior to heat waves which might include neighborhood watch, mobilized social

Town planners; social workers; communication workers and communal shelters, especially in poorer areas where heat waves have been shown to kill more people professionals

Engineering design or redesign of dwellings to achieve better thermal comfort

Engineers: architects; public health professionals

Modification of building codes to ensure minimal thermal standards

Engineers; architects; public health professionals

Development and installation of more cost-effective and less polluting

Engineers; architects air-conditioning systems

Redesigning urban landscapes to modify thermal exchanges between the built environment, ground and atmosphere, thereby reducing the heat island effect and increasing shade available in public space

Building water, food, energy and transport infrastructure systems that are more resilient to high temperature and able to deal with demand fluctuations during heat waves

processes and solutions that reduce the risk and/or manage it (e.g., McDonald, 2003; Au and Wang, 2014). However, the multitude of threats brought about by climate change and, more importantly, their unprecedented scale and magnitude, pose new challenges. Notably, conventional engineering responses to disaster management which have been effective, sufficient and/or cost-effective so far may no longer continue to be so.

Coastal flooding as a result of sea level rise is a case in point. Today, many coastal municipal councils around the world are planning for higher sea levels, and associated storm surges, projected by mid- to end of century. While engineering solutions such as sea walls (SW), beach nourishment (BN), and breakwaters (BW) can be implemented with the aim of keeping water out, increasingly, other options are being considered, namely strategic retreat (RT), i.e., organizing a total or partial withdrawal of communities from areas exposed to sea level rise-or allowing partial, controlled and periodic flooding (PF) with all the adjustment of the built environment that this entails (e.g., Begum et al., 2007; Zevenbergen et al., 2010; Shoalhaven Local Government Area, 2014).

All solutions above require stakeholder consultation and engagement to ensure the success of the intervention (Jha et al., 2012). However, for the more conventional set of measures (SW, BN, BW), it is possible to some extent, to separate the effort of designing and implementing the required technology from its social and ecological entanglements, interactions and implications - as engineers routinely do and are arguably most comfortable with. With the less conventional solutions (RT and $\mathrm{PF}$ ), however, this is no longer possible, since the technology is implemented in much closer proximity to and, stronger interactions with, people's lives, assets and social relations. While RT and $\mathrm{PF}$ still require physical modifications to the built environment, the primary focus of action is an adjustment of a community's modes of living and the way its members interact with the natural and built environments.

How does one compare the pros and cons of building a sea wall or conducting a beach nourishment operation with the social implications, costs and benefits, of a strategy of retreat and relocation of a community? Clearly, to be able to do so, engineers must engage with the social and ecological dimensions of technology, far more than they normally do. More specifically, a subtle shift of emphasis in the articulation of the goal of an anti-flooding intervention must occur: the aim is no longer the protection of the physical assets or infrastructure providing services to the community; rather, it is to shield or improve the well-being of the community living there, and this might require significant adjustments by the community itself. The difference in emphasis is crucial here because it allows engineers to expand the solution set available to them and to place actions of a predominantly technological nature (SW, BN, BW) in the same analytical framework as those that are more socially embedded (RT, PF). This shift can therefore help decision-makers, be they engineers or not, make comparisons and choices.

The emergence of a vulnerability and resilience paradigm over the last two decades is significant here (Adger, 2006; Füssel and Klein, 2006; Füssel, 2007; Tonmoy et al., 2014; El-Zein and Tonmoy, 2015). Vulnerability is a concept that incorporates risk but goes beyond it, recognizing that, ultimately, the goal of risk management is the protection of the well-being of communities and ecosystems, rather than the integrity of infrastructure systems providing them with services. The latter can, and usually is, part of the former but the two do not coincide. The most commonly used articulation of vulnerability, first provided by the International Panel on Climate Change (IPCC), makes explicit the separation between, on the one hand, the physical dimension of risk, through the concept of "exposure" to the hazard and, on the other hand, 


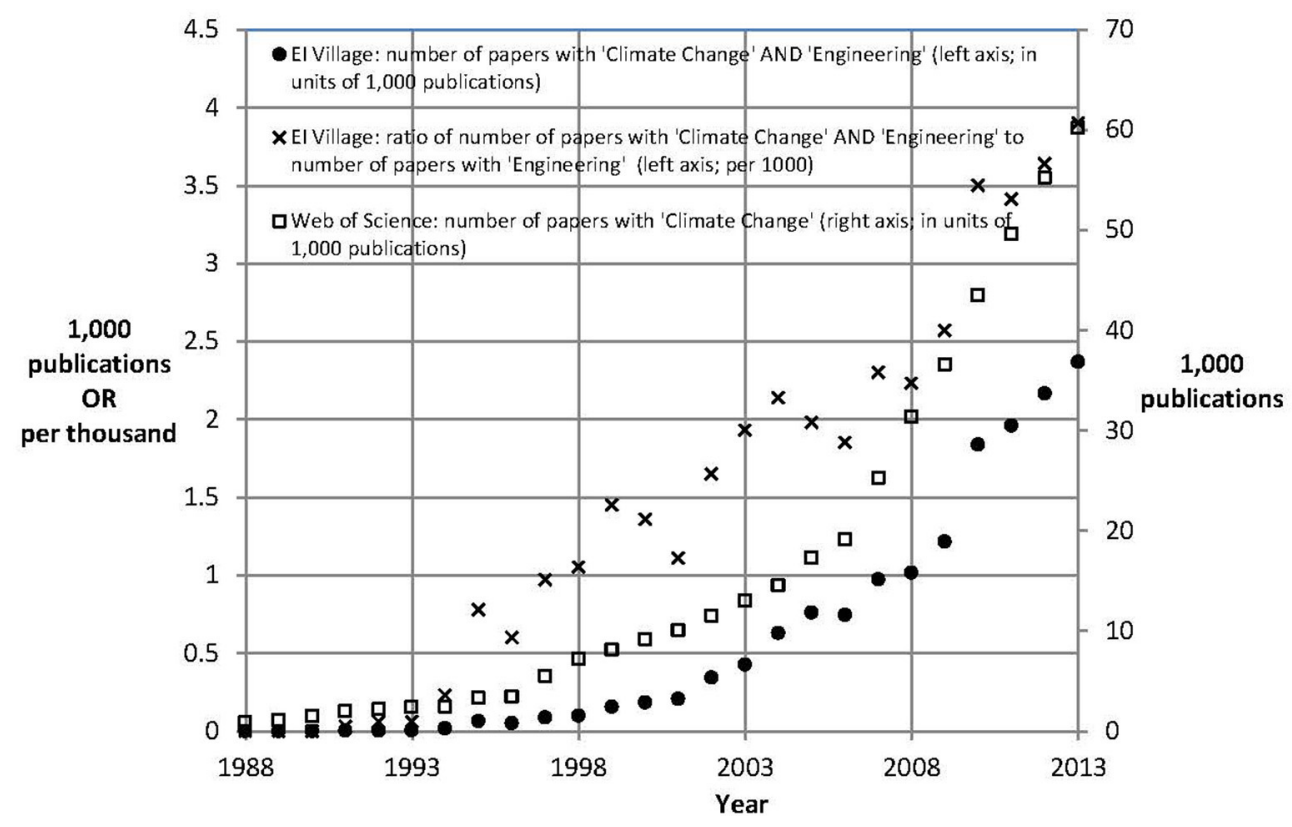

FIGURE 1 | Trends in number of publications making references to climate change in the engineering field from El Village, and in science generally from Web of Science (search conducted on 16 July 2014 and covered the widest available option in the records of each database: "all fields" in El Village and "topics" in Web of Science; El Village is an engineering and geosciences database; Web of Science is a general research database). its social, economic and institutional dimensions, through the notion of the "sensitivity" to the hazard of the social unit in question, and its "capacity to cope with and adapt to" it (IPCC, 2007).

No matter the conceptual tools adopted-and there are many-the key point here is that engineering curricula will need to reflect this shift in emphasis and move from conventional risk assessment to more socially-embedded analyses. This entails not just a broadening of conceptual thinking amongst students but acquiring skills in the use of new methodologies and simulation techniques that are not currently taught in conventional engineering degrees. Geospatial analyses, Geographical Information Systems (GIS) and participatory map making are one set of examples (e.g., Smith et al., 2000; Gorokhovich et al., 2013). Another example is the emergence of new simulation methods such as agent-based modeling which are highly suited for problems in which individual reactions to events, incentives and disincentives, aggregate into macroscopic behavior, within informationsensitive, data-intensive contexts (Janssen, 2005; Janssen and Ostrom, 2005). This is exactly the kind of problems encountered by engineers trying to predict the way different disaster contingency regimes combine with different patterns of individual and/or institutional behavior to produce different levels of damage and numbers of casualties (Scerri et al., 2012; Barahona et al., 2013).

Following from the discussion on coastal flooding above, Table 2 shows how the solution set considered by engineers can be expanded for a number of climate-related problems by including, in addition to conventional technology-focused actions, what I have called "socially-embedded" solutions. Here, three clarifications are in order.
First, it goes without saying that ALL engineering problems and solutions are located in the social space and are embedded in social institutions. What I refer to specifically as "sociallyembedded solutions" here are solutions which, as implied earlier, do not allow an easy separation of the technological and social elements of the intervention, at any of its stages, be it conception, design, implementation or operation.

Second, "socially-embedded solutions" almost always require strong technology input. However, the success of the technology in achieving its objectives, or lackthereof, is strongly linked to the way it is conceived of and implemented, received and embraced by communities and stakeholders.

Third, there is no implication here that "socially-embedded solutions" are somehow better or worse than technologydominated solutions: this will obviously depend on context. Once again, the example of coastal flooding is handy: below a certain threshold of sea-level rise, technological fixes such as sea walls may work best to keep water out; otherwise, partial flooding or strategic retreat may be a better option.

\section{POLITICS, BIAS, AND ENGINEERING DISCIPLINARY BOUNDARIES}

The expanded solution set shown in Table 2, calls for two kinds of engineering competencies, not usually emphasized in engineering university degrees. First, a stronger exposure and openness to key concepts and methodologies of other disciplines shown in Table 2 is critical. Second, engineers must be able to engage with communities in ways that involve listening to, communicating and working with stakeholders as partners rather than just recipients of engineering expertise and technology. For successive generations of engineers to be able to do so successfully, the social 
Table 2 | Expanded solution set through inclusion of socially-embedded actions.

\begin{tabular}{lll}
\hline Goal/Problem & $\begin{array}{l}\text { Conventional engineering solution set: examples } \\
\text { of technology-dominated solutions }\end{array}$ & $\begin{array}{l}\text { Expanded solution set: examples of more } \\
\text { socially-embedded solutions }\end{array}$ \\
\hline $\begin{array}{l}\text { Reducing global } \\
\begin{array}{l}\text { concentration of carbon } \\
\text { dioxide in the atmosphere }\end{array}\end{array}$ & $\begin{array}{l}\text { Improve energy efficiency of combustion engines } \\
\text { Develop more economical renewable sources of } \\
\text { energy (e.g., solar or wind energy) }\end{array}$ & $\begin{array}{l}\text { Reduce demand for energy } \\
\text { Switch to more energy efficient appliances } \\
\text { Switch to less energy-intensive modes of transport }\end{array}$ \\
\hline $\begin{array}{l}\text { Adapting to longer, more } \\
\text { frequent and more extreme } \\
\text { heat waves }\end{array}$ & $\begin{array}{l}\text { Develop more cost-effective air conditioning systems } \\
\text { Design households for better thermal comfort }\end{array}$ & $\begin{array}{l}\text { Create more shaded public spaces } \\
\text { Reduce the urban heat island effect through city landscaping } \\
\text { Reduce occupational exposure to heat through better work } \\
\text { shifts and protective gear }\end{array}$ \\
\hline $\begin{array}{l}\text { Adapting to more frequent } \\
\text { and more extreme flooding } \\
\text { events }\end{array}$ & $\begin{array}{l}\text { Increase the capacity of urban drainage systems } \\
\text { Build flood defenses such as sea walls }\end{array}$ & $\begin{array}{l}\text { Retreat from exposed coastal settlements } \\
\text { Allow partial flooding using floating structures }\end{array}$ \\
\hline $\begin{array}{l}\text { Adapting to more frequent } \\
\text { and more extreme drought } \\
\text { events }\end{array}$ & $\begin{array}{l}\text { Develop better water recycling systems } \\
\text { sevelop better protection of groundwater from }\end{array}$ & $\begin{array}{l}\text { Develop alternative sources of staple food } \\
\text { sevelop emergency water rationing systems } \\
\text { Adjust water pricing to reduce demand }\end{array}$ \\
\hline
\end{tabular}

embeddedness of technology needs to be debated, illustrated and well understood in engineering degrees far more than is routinely done. By social embeddeness of technology I mean the way technology changes, and is changed by, the social context in which it is conceived, designed, and deployed, i.e., the fact that it is inscribed within social relations and political institutions, rather than being somehow external to them (Giddens, 2009).

Indeed, recognizing the social-embeddedness of technology calls, in turn, for a departure in the way in which the "politics" of technology (and, by extension, engineering projects) are viewed by engineers. In my experience, "politics" are perceived by many engineering students, graduates and practitioners as, at best, an impediment to the benevolent deployment of technology and technocratic expertise and, at worst, as a destructive force through which narrow-minded self interests can wreak projects and prevent progress. While disfunctional politics can certainly cause such damage, well-functioning "politics," on the other hand, should be seen as an indispensable and healthy framework within which social agents and institutions, including engineers and engineering firms, negotiate processes of technology-driven change by bringing to bear their different perspectives and interests. Such a framework, provided it is governed by rules and laws that are sufficiently transparent, democratic and fair, can ensure far better outcomes for engineering projects and the common good they serve.

Inevitably, a healthy engagement with the politics of technology requires a good deal of self-reflection on the part of engineers about their own interests, biases and knowledge acquisition methods-both as members of a managerial class invested with technocratic power and privilege and as employees of engineering firms with specific commercial interests (e.g., Riley, 2008; Leydens et al., 2012). One example is the role that engineers can and do play in the long-term transition into a carbonneutral energy systems and the choices to be made between the array of technological, economic, financial and political tools and means available to achieve such a transition. Given the extent to which engineering know-how is heavily invested in supply-side of services and large infrastructure systems, it is legitimate to ask whether the self-interest of engineers might compromise the neutrality of their scientific positions and advice. Clearly, there is no simple answer to this question-some engineers and engineering organizations will retain their neutrality while others won't-and it will depend on the specific context, industrial, cultural and national. However, it is a question that engineers need to be thinking about and certainly engineering students need to be asking, analysing and reflecting upon.

Another way of making this point is to argue that engineering professionals, institutions and Universities need to better articulate the social good that engineering serves-something the engineering profession may have taken for granted until now but which needs far more reflection on the part of engineers than before. Small (1983) saw wealth generation as the primary task of engineers, though he did not specify wealth for whom exactly, and at what cost to whom. Mitchell et al. (2004) and Pielke (2008), on the other hand, argued that engineers should play the role of an "honest broker" acting as knowledge providers and technology experts in conflicts around technology. Dong (2008) built on the capabilities approach of Sen (1999) and Nussbaum (1995) to propose an ethics of design that enhances the "capacity of people to live the life that they value." El-Zein and Hedemann (2013) showed how one particular formulation of the social good of engineering - "provision of access to safe water, air, food, habitat and means of transport, as fundamental human rights" — can serve to highlight the somewhat arbitrary, and possibly counterproductive, nature of the current disciplinary divisions between civil, mechanical and electrical engineering.

It is no accident that, over the last two decades, a number of engineering researchers and educators have been calling for a broadening of engineering curricular focus to encompass problem definition and not just problem solving (Downey, 2005), social and environmental decision-making paradigms (El-Zein et al., 2008), creative design approaches that incorporate human factors in design (Holt et al., 1985) as well history, social justice, globalization, environmental sustainability and politics (e.g., 
Baillie, 2006; El-Zein et al., 2008; Bell, 2011). Downey (2005) warned that, unless engineers become involved in problem definition, and are able to critically reflect on it, they risk turning into "technical functionaries in support positions."

Clearly, the broadening of the curriculum is no easy feat, given continuous pressure for the inclusion of new technical subject matter and industry-relevant applied knowledge. This is precisely why an expansion into some of the areas discussed above is not just a matter of adding a few courses here and there. It requires instead a serious examination and realignment of curricula, in light of new ecologically-driven demands likely to be made on engineers in the twenty-first century. Such an appraisal should cover not just content, graduate attributes and learning outcomes of engineering university programs but other variables that are not often questioned, such as number of years for engineering degrees, undergraduate vs. post-graduate structures of engineering studies, the usefulness of conventional divisions between engineering disciplines and the relationship between engineering and physical and social sciences within the academy.

In fact, over the last decade, in attempting to better integrate engineering with relevant social and ecological disciplines, some universities have operated at an institutional level, creating new degree programs combining engineering with ecology, public health or social sciences and setting engineering departments or research centers within a bigger science-based structure. Whether this is desirable, feasible and/or effective will depend on context. However, these changes should serve to remind us that a radical re-appraisal of the way we do things is possible and desirable.

\section{CONCLUSIONS}

Modern-day engineering-including its professional institutions and university curricula-emerged, by and large, in the early to mid-twentieth century, when economic and population growth and the rise of mass production and consumption were leading to further expansion of cities and more intensive use of urban space. Hence, engineers saw it as their task to build fundamental infrastructures for commercial, industrial and residential sectors (e.g., city, inter-city and international transport; automated production lines and processes for manufacturing; high-rise buildings; cheaper, more compact and more comfortable housing; food production through intensive agriculture; water and waste-water systems for better public health). A focus on large infrastructure, "big engineering" and mass supply of energy, food and water have characterized the profession ever since.

Building, modernizing and maintaining infrastructure systems still is, and will no doubt remain, an essential part of the work of engineers. However, the kind of challenges that engineers are faced with in the post-industrial, information-intensive societies of the twenty-first century, are markedly different to those of the one that preceded it. An important new element is the strong need today to address the anthropogenic threats to the ecological basis of life and the depletion and degradation of natural resources. Most of these threats are moderated by technology that engineers and scientists conceive of, build and maintain. Conversely, many of the responses to these threats are likely to draw on technology developed by engineers and scientists. This challenge has at least two important implications for engineering. First, it requires engineers to build and operate within solution sets that go well beyond conventional large-scale, supply-side engineering. Second, it makes it imperative for engineers to become more conscious, and more willing to engage with, the social and ecological embeddedness of technology and its political dimensions. Otherwise, engineers risk becoming technical wizards in the service of bigger and better minds, failing in their role as intelligent agents of technology-driven change who are capable of addressing the complex challenges of the twenty-first century.

\section{REFERENCES}

Adger, W. N. (2006). Vulnerability. Glob. Environ. Change 16, 268-281. doi: 10.1016/j.gloenvcha.2006.02.006

Au, S. K., and Wang, Y. (2014). Engineering Risk Assessment with Subset Simulation. (Singapore: John Wiley \& Sons), 336.

Baillie, C. (2006). Engineers within a Local and Global Society. Colorado: Morgan and Claypool Publishers.

Barahona, F., Ettl, M., Petrik, M., and Rimschnik, P. M. (2013). "Agile logistics simulations and optimisation for managing disaster responses," in Proceedings of the 2013 Winter Simulation Conference (Washington, DC: IEEE), 3340-3351.

Begum, S., Stive, M. J. F., Hall, J. W. (eds.). (2007). Flood Risk Management in Europe. Innovation in Policy and Practice. Dordrecht: Springer, 534.

Bell, S. (2011). Engineers, Society and Sustainability. Synthesis Lectures on Engineers, Technology and Society. Colorado: Morgan and Claypool Publishers.

Dalton, J. C., DeLoach, S. R., Arnold, J. R., and White, K. D. (2012). Engineering for climate change adaptation at the US Army Corps of engineers: policy, plans and projects. Soc. Petrol. Eng. 2, 1154-1165. doi: 10.7122/ 153149-MS

Dong, A. (2008). The policy of design: a capabilities approach. Des. Issues $24,76-87$. doi: 10.1162/desi.2008.24.4.76

Downey, G. L. (2005). Keynote lecture: are engineers losing control of technology? From "Problem Solving" to "Problem Definition and Solution" in engineering education. Chem. Eng. Res. Des. 83, 1-12. doi: 10.1205/cherd.05095

El-Zein, A., Airey, D., Bowden, P., and Clarkeburn, H. (2008). Sustainability and ethics as decision-making paradigms in engineering curricula. Int. J. Sustainabil. High. Educ. 9, 170-182. doi: 10.1108/14676370810856314

El-Zein, A., and Hedemann, C. (2013). "Engineers as problem solvers: a deficient self-definition in the 21st century," in Engineering Education for Sustainable Development EESD13 (Cambridge: University of Cambridge), 1-8. Available online at: http://www-eesd13.eng.cam.ac.uk/proceedings/papers/ 22-engineers-as-problem-solvers-el-zein-and.pdf

El-Zein, A., and Tonmoy, F. (2015). Assessment of vulnerability to climate change using a multi-criteria outranking approach with application to heat stress in Sydney. Ecol. Indic. 48, 207-217. doi: 10.1016/j.ecolind.2014.08.012

Füssel, H. M. (2007). Vulnerability: a generally applicable conceptual framework for climate change research. Glob. Environ. Change 17, 155-167. doi: 10.1016/j.gloenvcha.2006.05.002

Füssel, H. M., and Klein, R. (2006). Climate change vulnerability assessments: an evolution of conceptual thinking. Clim. Change 75, 301-329. doi: 10.1007/s10584-006-0329-3

Giddens, A. (2009). The Politics of Climate Change. Cambridge: Polity Press, 130.

Gorokhovich, Y., Leiserowitz, A., and Dugan, D. (2013). Integrating coastal vulnerability and community-based subsistence resource mapping in Northwest Alaska. J. Coast. Res. 30, 158-169. doi: 10.2112/JCOASTRES-D-1300001.1

Holt, J. E., Radcliffe, D. F., and Schoorl, D. (1985). Design or problem solving-a critical choice for the engineering profession. Des. Stud. 6, 107-110.

IPCC. (2007). "Climate change 2001: impacts, adaptation and vulnerability," in Contribution of Working Group II to the Fourth Assessment Report of the Intergovernmental Panel on Climate Change, eds J. J. McCarthy, O. F. Canziani, N. A. Leary, D. J. Dokken, and K. S. White (Cambridge: Cambridge University Press), 976.

Janssen, M. A. (2005). "Agent-based modelling," in Modeling in Ecological Economics, eds J. Proops and P. Safonov (Cheltenham: Edward Elgar Publishing), 155-172.

Janssen, M. A., and Ostrom, E. (2005). "Governing social-ecological systems," in Handbook of Computational Economics II: Agent-Based Computational 
Economics, eds K. L. Judd and L. Tesfatsion (Amsterdam: Elsevier Publisher), 1465-1509.

Jha, A., Bloch, R., and Lammond, J. (2012). Cities and Flooding: A Guide To Integrated Flood Risk Management for the 21st Century. Washington, DC: World Bank Publications.

Leydens, J. A., Lucena, J. C., and Schneider, J. (2012). Are engineering and social justice (in)commensurable? A theoretical exploration of macro-sociological frameworks. Int. J. Eng. Soc. Justice Peace 1, 63-82. Available online at: http://library.queensu.ca/ojs/index.php/IJESJP/article/view/3507/4317

McDonald, D. (2003). Industrial Safety, Risk Assessment and Shutdown Systems. Newnes: Elsevier, 384.

Mitchell, C. A., Carew, A., and Clift, R. (2004). "The role of the professional engineer and scientist in sustainable development," in Sustainable Development in Practice, eds A. Azapagic, S. Perdan, and R. Clift (London: John Wiley \& Sons), Chapter 2.

Nussbaum, M. C. (1995). "Human capabilities, female human beings," in Women, Culture, and Development: A Study of Human Capabilities, eds Martha C. Nussbaum and J. Glover (Oxford: Clarendon Press), 492.

Pielke, R. A. (2008). The Honest Broker: Making Sense of Science in Policy and Politics. Cambridge: Cambridge University Press.

Riley, D. (2008). Engineering and Social Justice. San Rafael, CA: Morgan \& Claypool.

Scerri, D., Hickmott, S., Bosomworth, K., and Padgham, L. (2012). Using modular simulation and agent based modelling to explore emergency management scenarios. Aust. J. Emerg. Manage. 27, 44-48. Available online at: http://www.cs.rmit.edu.au/agents/www/agentsbib/auto-generated/papers/ ajem12-shbp.pdf

Shoalhaven Local Government Area. (2014). Coastal Public Safety Risk Assessment. Belrose: Surf life saving NSW, 150.

Royal Academy of Engineering. (2011). Infrastructure, Engineering and Climate Change Engineering-Ensuring Services in an Uncertain Future. The Royal Academy of Engineering on behalf of Engineering the Future, 3 Carlton House Terrace London SW1Y 5DG, 108. Available online at: https://www.gov.uk/government/uploads/system/uploads/attachment_data/file/ 183536/infrastructure-rae-report.pdf

Sen, A. K. (1999). Development as Freedom. Oxford: Oxford University Press.

Small, B. W. (1983). Wealth generation-our essential task. Proc. Inst. Eng. 197B, 131-141

Smith, K., Barett, C. B., and Box, P. W. (2000). Participatory risk mapping for targeting research and assistance: with an example from East African pastoralists. World Dev. 28, 1945-1959. doi: 10.1016/S0305-750X(00) 00053-X

Tonmoy, F., El-Zein, A., and Hinkel, J. (2014). Assessment of vulnerability to climate change using indicators: a meta-analysis of the literature. WIREs Clim. Change. doi: 10.1002/wcc.314. [Epub ahead of print].

Zevenbergen, C., Cashman, A., Evelpidou, N., Pasche, E., Garvin, S., and Ashley, R. (2010). Urban Flood Management. Florida: CRC Pres, 310.

Conflict of Interest Statement: The author declares that the research was conducted in the absence of any commercial or financial relationships that could be construed as a potential conflict of interest.

Received: 12 August 2014; accepted: 30 September 2014; published online: 16 October 2014.

Citation: El-Zein AH (2014) Risk and social vulnerability: how engineering can engage more effectively with climate change. Front. Environ. Sci. 2:43. doi: 10.3389/fenvs. 2014.00043

This article was submitted to Interdisciplinary Climate Studies, a section of the journal Frontiers in Environmental Science.

Copyright $\odot 2014$ El-Zein. This is an open-access article distributed under the terms of the Creative Commons Attribution License (CC BY). The use, distribution or reproduction in other forums is permitted, provided the original author(s) or licensor are credited and that the original publication in this journal is cited, in accordance with accepted academic practice. No use, distribution or reproduction is permitted which does not comply with these terms. 